\title{
Endotoxin Contamination in Nanomaterials Leads to the Misinterpretation of Immunosafety Results
}

\author{
Yang $\mathrm{Li}^{1 *}$, Mayumi Fujita ${ }^{1}$ and Diana Boraschi ${ }^{2}$ \\ ${ }^{1}$ Department of Dermatology, University of Colorado, Anschutz Medical Campus, Aurora, CO, USA, \\ ${ }^{2}$ Institute of Protein Biochemistry, National Research Council (CNR), Napoli, Italy
}

OPEN ACCESS

Edited by:

Claudia Monaco,

University of Oxford, UK

Reviewed by:

Laleh Majlessi,

Institut Pasteur, France

Martin Himly,

University of Salzburg, Austria

${ }^{*}$ Correspondence:

Yang Li

yang.li.nano@gmail.com,

yang.3.li@ucdenver.edu

Specialty section: This article was submitted to Inflammation,

a section of the journal

Frontiers in Immunology

Received: 28 December 2016 Accepted: 05 April 2017

Published: 08 May 2017

Citation:

Li Y, Fujita M and Boraschi D (2017) Endotoxin Contamination in

Nanomaterials Leads to the

Misinterpretation of Immunosafety

Results.

Front. Immunol. 8:472. doi: 10.3389/fimmu.2017.00472
Given the presence of engineered nanomaterials in consumers' products and their application in nanomedicine, nanosafety assessment is becoming increasingly important. In particular, immunosafety aspects are being actively investigated. In nanomaterial immunosafety testing strategies, it is important to consider that nanomaterials and nanoparticles are very easy to become contaminated with endotoxin, which is a widespread contaminant coming from the Gram-negative bacterial cell membrane. Because of the potent inflammatory activity of endotoxin, contaminated nanomaterials can show inflammatory/toxic effects due to endotoxin, which may mask or misidentify the real biological effects (or lack thereof) of nanomaterials. Therefore, before running immunosafety assays, either in vitro or in vivo, the presence of endotoxin in nanomaterials must be evaluated. This calls for using appropriate assays with proper controls, because many nanomaterials interfere at various levels with the commercially available endotoxin detection methods. This also underlines the need to develop robust and bespoke strategies for endotoxin evaluation in nanomaterials.

Keywords: engineered nanomaterials, immunosafety assessment, endotoxin contamination, endotoxin evaluation, Limulus amebocyte lysate assay

\section{INTRODUCTION}

Nanotechnology has undergone a rapid growth all over the world, with the production of a broad array of different nanomaterials in many consumers' products, to which the human population and the environment are therefore increasingly exposed. The health and environmental impacts of these new engineered nanomaterials (ENM) are a topic of considerable interest for nanotech industries and regulators as well as scientists, leading to the attempt of building safe-by-design ENM and the effort of establishing clear and relevant safety guidelines (1). Among nanotoxicity effects, induction of inflammation is considered a risk-predictive key effect (2). Several ENM were found to trigger inflammation in experimental models both in vitro and in vivo, suggesting a possible risk for human health (3-7). However, many experimental studies that show inflammatory effects triggered by ENM did not properly consider the possible presence of endotoxin. The Gram-negative endotoxin or lipopolysaccharide (LPS) is a ubiquitous contaminant in our environment and a potent inducer of inflammation and cell death. Hence, when evaluating the toxic and inflammatory effects of ENM to establish their safety, we must be aware that the presence of endotoxin in ENM can lead to inaccurate findings and consequently misleading conclusions (8). 
Endotoxin/LPS is a molecule found in the outer membrane of Gram-negative bacteria and consists of a hydrophilic polysaccharide domain and a hydrophobic lipid domain. LPS plays an important role in bacterial virulence, because of its lipid part (lipid A) responsible for cytotoxicity. In mammalian tissues, LPS binds to a soluble LPS-binding protein, which transports LPS to the cell surface receptor, Toll-like receptor (TLR) 4. TLR4, together with MD2 and CD14, initiates signaling that leads to activation of inflammation pathways in different cell types (9). Because TLR4 is expressed by many cells, in particular innate immune cells such as monocytes and macrophages, these cells are very sensitive and responsive to LPS stimulation and raise a defensive inflammatory response against bacterial infections (10). LPS-activated cells produce and secrete a great number of inflammatory factors including interleukin (IL)-1 $\beta$, IL-6, IL-8, and tumor necrosis factor- $\alpha$. At high concentrations, LPS can also directly kill cells, although it depends on cell sensitivity. Given its potent inflammatory/toxic activity, exposure to endotoxin can induce serious and even life-threatening effects, including respiratory symptoms, asthma, and endotoxemia (11-14). Therefore, the acceptable endotoxin levels in medical products (such as surgical instruments or drugs) have been regulated by US FDA as early as 1985, updated thereafter, and accepted/adopted almost all over the world (15). Pharmaceutical companies must follow these regulations, and the presence of endotoxin in medical use products or intravenous (i.v.) drugs must be certified to be below a given limit before their release in the market. However, this regulation does not apply to ENM that are not intended for medical use, meaning that most industrially produced ENM are not screened for endotoxin contamination. While this may not be a health problem unless the ENM are administered i.v. into human beings, it still remains a relevant issue because the results from extremely sensitive nanosafety models used for assessing products' safety may be biased by the presence of contaminating endotoxin and reveal inflammatory/toxic effects that are not ENM specific but rather endotoxin dependent.

\section{ENDOTOXIN CONTAMINATION OF NANOMATERIALS}

Endotoxin is a thermoresistant molecule that can persist in the environment in the absence of live Gram-negative bacteria. Its thermostability makes endotoxin resistant to the routine sterilization methods applied in biology laboratories (16). Thus, endotoxin is a ubiquitous environmental contaminant, present in all chemicals and glassware used in laboratories (17). Special attention or treatment is needed for avoiding/eliminating endotoxin contamination, which includes working in endotoxin-free conditions and depyrogenation of materials. A common and effective method for depyrogenation is incineration, which implies dry heating of tools and materials at high temperatures for given times, e.g., $180^{\circ} \mathrm{C}$ for $3 \mathrm{~h}$ or $250^{\circ} \mathrm{C}$ for $30 \mathrm{~min}$ (18). However, these extreme conditions are not suitable for depyrogenating most ENM, because the treatment may change the ENM physicochemical properties. França et al. used different methods (UV irradiation, gas-plasma treatment, ethylene oxide treatment, formaldehyde treatment, and autoclaving) for sterilizing/depyrogenizing two differently sized gold ( $\mathrm{Au}$ ) nanoparticles
(NPs). They found that the various methods caused changes in the $\mathrm{Au}$ NPs, the most common problem being NPs aggregation and consequent changes in UV-Vis spectra, morphology, and particle size distribution. They further tested the biological effects of these $\mathrm{Au}$ NPs and found that the different sterilization procedures could affect the NPs cytotoxic capacity and their ability to induce intracellular ROS (19). Hence, the best way to obtain endotoxin-free ENM is to take precautions and synthesize them in endotoxin-free conditions (20). As most chemical labs and manufactures do not apply particular precautions, the ENM undergoing nanosafety and preclinical nanomedicine efficacy studies are likely to get contaminated by endotoxin. Furthermore, ENM have a large reactive surface area, which tends to absorb molecules from the surrounding milieu to reduce its energy, thereby facilitating the adsorption of surface contaminants (21). The lipid domain allows endotoxin attachment to hydrophobic surfaces, while the negatively charged phosphate groups promote endotoxin interaction with cationic surfaces (22). In addition, coordinative binding can occur between the negatively charged LPS and loosely anionic surfaces (e.g., citrate-coated Au NPs), resulting in firm and stable binding (23). ${ }^{1}$ Therefore, endotoxin can attach to virtually any surface, which makes endotoxin a common contaminant for many different kinds of $\operatorname{ENM}(8,21)$. Darkow and coworkers have shown that functionalized NPs could bind endotoxin through Coulomb and van der Waals interactions (24). Bromberg et al. showed a strong interaction between lipid A (the toxic moiety of endotoxin) and functionalized paramagnetic ENM (25). The capacity of endotoxin to bind with NPs was also observed for polystyrene particles (26). Our recent study showed that endotoxin binds to the surface of Au NPs in a dose-dependent manner (23). Abadeer et al. studied the role of surface properties in the interaction of Au nanorods with endotoxin by using surface plasmon resonance sensing and found that endotoxin attaches more easily to a cationic surface compared to neutral or anionic surfaces (27). Our data with Au NPs indeed confirm that the ENM surface characteristics can affect the binding of endotoxin (23, see text footnote 1).

We have lab tested several commercial ENM or ENM received from collaborators and found variable degrees of endotoxin contamination (unpublished data; Figure 1A). In a study in which NPs synthesis was repeated in normal conditions or after glassware and tool depyrogenation, we could show that taking precautions could significantly dampen the endotoxin contamination in ENM (28). On the other hand, a heavy endotoxin contamination in polystyrene ENM after long-term storage (over 6 months) may have been due to the poor handing processes (29). Thus, we should be aware that endotoxin contamination in ENM is a common phenomenon.

\section{BIOLOGICAL EFFECTS OF ENDOTOXIN- CONTAMINATED NANOMATERIALS}

The biological effects of endotoxin-contaminated ENM have been reviewed recently (8). Endotoxin-carrying ENM can initiate the

${ }^{1}$ Li Y, Shi Z, Radauer-Preiml I, Andosch A, Casals E, Luetz-Meindl U, et al. Bacterial Endotoxin (LPS) Binds to the Surface of Gold Nanoparticles, Interferes with Biocorona Formation and Induces Human Monocyte Inflammatory Activation. 

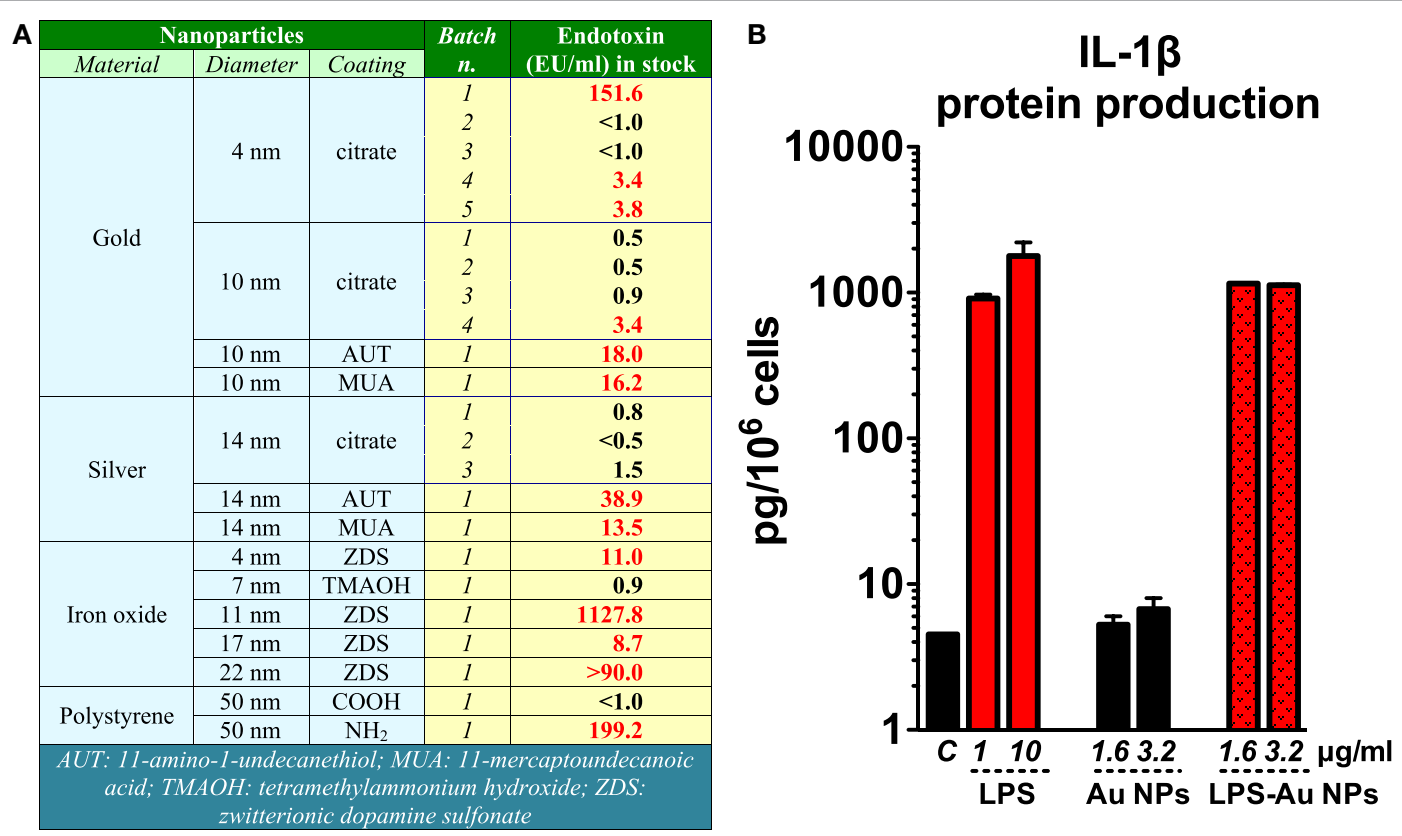

FIGURE 1 | Endotoxin contamination in nanoparticles (NPs) induces inflammatory effects. (A) Endotoxin contamination in different nanomaterials evaluated by Limulus amebocyte lysate assay. (B) Gold (Au) NPs were deliberately contaminated with $1 \mathrm{\mu g} / \mathrm{ml}$ lipopolysaccharide (LPS) for $1 \mathrm{~h}$ at room temperature and then thoroughly washed with endotoxin-free water to eliminate unbound LPS. Human primary monocytes were exposed to either endotoxin-free or endotoxin-coated Au NPS for $24 \mathrm{~h}$. The production of interleukin (LL)-1 $\beta$ in the culture supernatants was measured by ELISA [data partially presented in the supporting material of Ref. (30)].

TLR4 signaling pathway in innate immune cells, activate the inflammasome, and induce the secretion of IL-1 $\beta$, a fundamental cytokine that plays an important role in physiological and pathological conditions (31), as well as many other inflammation-related factors. We have shown that the endotoxin bound on the surface of Au NPs turned those NPs from inactive to highly inflammatory and able to induce secretion of IL-1 $\beta$ in human primary monocytes (Figure 1B) (30). With this in mind, many reports that show inflammatory and toxic effects of ENM in vitro or in vivo on TLR4-expressing cells need to be taken with caution if the endotoxin level was not assessed. Studies have shown that ENM can activate a TLR4-dependent inflammatory response in the target cells. Some of these studies failed to assess or did not mention the potential contamination of the ENM under study with endotoxin $(32,33)$, which makes it impossible to assess the reliability of the results. On the other hand, other studies showed the ability of ENM to initiate TLR4-dependent activation in the absence of measurable endotoxin contamination or by excluding the effects of endotoxin [see, for instance, Ref. (34)], thereby suggesting a bona fide ENM effect. Qu et al. reported that graphene oxide can be sensed by TLR4 and induce macrophage necrosis through the caspase-3 pathway (35). Endotoxin was measured in this study with a Limulus amebocyte lysate (LAL) endpoint chromogenic kit from Lonza and declared to be about $0.1 \mathrm{EU} / \mathrm{ml}$ ( $1 \mathrm{ml}$ containing $80 \mu \mathrm{g}$ of NPs). This brings us to another concern, i.e., the possible interference of graphene oxide with the LAL assay. Indeed, interference has been extensively reported for many ENM (36-39), which strongly suggests the need for testing the interference for each ENM under investigation. In addition, the Lonza QCL-1000 endpoint chromogenic LAL assay with readout at $405 \mathrm{~nm}$ has been shown to be unsatisfactory for measuring endotoxin in metal and metal oxide (39) as well as graphene oxide ENM (40). With all this in mind, we conclude that not only should we measure endotoxin in ENM but also we must make sure that the endotoxin detection assay is reliable and relevant to the ENM under study. Without the formal proof of the absence of endotoxin contamination, the bona fide bioeffects of ENM cannot be accurately assessed.

\section{ENDOTOXIN EVALUATION METHODS IN NANOMATERIALS}

The FDA-approved methods to detect endotoxin are the rabbit pyrogen test (RPT) as an in vivo test and the LAL assay as an in vitro test. Alternative and sensitive bioassays are also approved by the European Centre for the Validation of Alternative Methods (ECVAM) for assessing pyrogens, such as the human PBMC activation assay and the human monocytes activation test (MAT). However, the RPT in vivo assay and in vitro bioassays using PBMC and monocytes are not specific for endotoxin, because they measure inflammatory effects (induction of fever and induction of inflammatory cytokines) and thus detect responses from all types of inflammation-inducing agents (which may include EMN). Therefore, to specifically detect the endotoxin level in ENM, the LAL assay is recommended.

The LAL assay could provide fast, sensitive, and specific endotoxin assessment. The only other molecule that gives a positive result with the traditional LAL assay is $\beta$-glucan, which, however, can be inhibited by a specific buffer in the currently available commercial LAL kits. Because of its specificity, sensitivity, and reliability, the LAL assay has replaced the old in vivo RPT as the assay chosen by all regulatory agencies, such as FDA, European, 
TABLE 1 | Advantages and disadvantages of assays used to detect endotoxin

\begin{tabular}{|c|c|c|c|c|c|c|}
\hline \multicolumn{5}{|c|}{ Limulus amebocyte lysate (LAL) assay } & \multicolumn{2}{|r|}{ Bioassay } \\
\hline \multicolumn{3}{|c|}{ Traditional } & \multicolumn{2}{|r|}{ Modified } & \multirow[t]{2}{*}{ Rabbit pyrogen test } & \multirow[t]{2}{*}{ In vitro activation assay } \\
\hline Gel clot & Turbidimetric & Chromogenic & Fluorogenic & EndoLISA & & \\
\hline \multicolumn{5}{|c|}{ Short-term experiment and easy performance, specific for endotoxin, most used endotoxin measurement methods } & \multirow{2}{*}{\multicolumn{2}{|c|}{$\begin{array}{l}\text { Most relevant assays for pyrogen detection can be used to screen } \\
\text { nanomedicine for preclinic usage }\end{array}$}} \\
\hline Easy and cheap & $\begin{array}{l}\text { Quantitative, high } \\
\text { sensitivity }\end{array}$ & $\begin{array}{l}\text { Quantitative, high } \\
\text { sensitivity, two } \\
\text { different detection } \\
\text { wavelengths }\end{array}$ & $\begin{array}{l}\text { High sensitivity, } \\
\text { very specific } \\
\text { (no recognition of } \\
\beta \text {-glucan) }\end{array}$ & $\begin{array}{l}\text { Washing steps can eliminate } \\
\text { interfering substances compared } \\
\text { to other LAL assays, wide } \\
\text { endotoxin detection range }\end{array}$ & & \\
\hline \multirow[t]{2}{*}{$\begin{array}{l}\text { Semiquantitative, low sensitivity, } \\
\text { prone to subjective variations, not } \\
\text { precise, proved to be interfered } \\
\text { by nanoparticles (NPs) }\end{array}$} & \multirow{2}{*}{$\begin{array}{l}\text { Due to their turbidity, } \\
\text { high optical density } \\
\text { NPs or NPs at high } \\
\text { concentration may } \\
\text { interfere with this } \\
\text { assay }\end{array}$} & \multirow{2}{*}{$\begin{array}{l}\text { Can be interfered } \\
\text { by NPs with } \\
\text { absorbance at or } \\
\text { close the detection } \\
\text { wavelength ( } 405 \text { or } \\
540 \mathrm{~nm})\end{array}$} & \multirow[t]{2}{*}{$\begin{array}{l}\text { NPs may interfere } \\
\text { with enzyme } \\
\text { reaction or quench } \\
\text { fluorescence }\end{array}$} & \multirow{2}{*}{$\begin{array}{l}\text { NPs may interfere with } \\
\text { lipopolysaccharide (LPS) antibody } \\
\text { binding. Not clear if washing } \\
\text { could detach LPS (bound to the } \\
\text { wells) from particles, or remove } \\
\text { LPS from wells together with } \\
\text { particles, or leave LPS-coated } \\
\text { particles in the wells. Residual } \\
\text { particles in wells, if not washed } \\
\text { off, may interfere with enzyme } \\
\text { reaction or quench fluorescence }\end{array}$} & \multicolumn{2}{|c|}{$\begin{array}{l}\text { Non-specific for endotoxin, reactive to any inflammation-inducing } \\
\text { agent (including some NPs). The interference of NPs with these } \\
\text { assays still needs accurate evaluation }\end{array}$} \\
\hline & & & & & $\begin{array}{l}\text { Animal usage, high } \\
\text { cost, low sensitivity }\end{array}$ & $\begin{array}{l}\text { NPs may induce cytotoxicity and interfere } \\
\text { with cell activation in vitro. NPs may } \\
\text { also interfere with the ELISA procedures } \\
\text { used for detecting inflammatory factors } \\
\text { (e.g., antibody-antigen binding, color } \\
\text { development, optical readouts) }\end{array}$ \\
\hline
\end{tabular}

Use NPs interference should be predetermined (e.g., turbidity, the optical interference). Appropriate procedures could be also applied to overcome interference, such as dilution or switching to another detection wavelength. Additional controls should be run to exclude interference with assay components (e.g., measuring endotoxin recovery rate)

decision is usually made based on the gel clot assay

in industry. This regulation is,

however, unsuitable for NPs

because of their significant

interference with the assay
Applied to NPs that Commonly used interfere with the assay in biology

chromogenic assay labs. Can be

used with NPs

after appropriate

controls
May be used

for NPs that

do not have

autofluorescence

and do not quench

fluorescence

Can be applied in combination with the LAL assay for analyzing the parenteral drugs (nanodrug) during the earlier development phase. Generally used when different LAL assays show $>25 \%$ variation.

Use for NPs should be accurately solving the problem validated (see Cons above) 
Chinese, and Japanese pharmacopeias (41-44). The use of the LAL assay for endotoxin detection in ENM is also regulated by ISO29701:2010 regulation "Nanotechnologies-Endotoxin test on nanomaterial samples for in vitro systems" (45).

In the LAL assay, factor C, an enzyme derived from the amebocytes of the horseshoe crab Limulus polyphemus, is activated by exposure to endotoxin and in turn induces activation of a clotting enzyme. Based on the types of detection of the clotting enzyme activity, three variants of the LAL assay are commercially available, including the gel clot, the turbidimetric, and the chromogenic assays. Recently, using recombinant factor $\mathrm{C}$ instead of the Limulus amebocyte lysate, new fluorescence-based assays have been developed. These assays have the advantage of being totally specific for endotoxin, because $\beta$-glucan activates factor $\mathrm{G}$ but not factor $\mathrm{C}$. Although the LAL assay can reliably detect endotoxin in soluble reagents, the physicochemical characteristics of ENM pose a significant problem of interference with both the components and the detection readouts (fluorescence, optical density) of various assays $(28,36,39)$. To overcome the interference problem, the available assays need to be validated for the lack of interference by ENM with the catalytic activity of the enzyme(s), substrate cleavage, and the final readout signals $(8,39)$. It has been shown that the gel clot LAL assay is not accurate for testing endotoxin contamination in particles, while the chromogenic LAL assay showed higher sensitivity and no interference (46). The unsuitability of the gel clot assay has also been shown for silica, silver (Ag), titanium dioxide, calcium carbonate, and other clinical-grade NPs $(37,38,47)$, suggesting that the gel clot assay should not be used for testing endotoxin in ENM in general. However, despite these new evidences, the use of the gel clot assay is still recommended in a FDA guidance document to solve discrepancies between results from different LAL formats in industry (48). Furthermore, our results with the chromogenic LAL assay suggested that metal and metal oxide NPs may interfere with the final readout by absorbing the final dye (p-nitroaniline) and quenching the readout, leading to underestimating the endotoxin contamination (39). Therefore, Dobrovolskaia et al. have declared that none of the currently available LAL formats is optimal for endotoxin assessment in ENM and suggested that at least two LAL formats with different endpoints/readouts should be used. The results should also be confirmed by RPT when the LAL results show more than $25 \%$ difference $(36,38)$. This approach has been used at the Nanotechnology Characterization Laboratory of the National Cancer Institute (USA) for measuring the endotoxin contamination in ENM.

The bioassays, on the other hand, may be adequate to assess pyrogenic/inflammatory effects in general, in particular for the ENM for clinical use. These bioassays (RPT in vivo and PBMC and MAT in vitro) are not specific for endotoxin, since they are based on the development of an inflammatory response (e.g., fever, NF- $\mathrm{kB}$ activation, secretion of inflammatory cytokines), which can be induced by any kind of pyrogen, theoretically including ENM. Therefore, bioassays cannot distinguish between effects induced by endotoxin and other pyrogens and intrinsic effects of ENM. The use of the PBMC or the MAT tests in parallel to the LAL assay should allow us to detect, in addition to endotoxin, the possible presence of other pyrogenic agents, which may be present but cannot be detected with the LAL assays. Thus, Dobrovolskaia et al. suggested to use such assays to confirm the LAL results (38). We have tested endotoxin contamination in $\mathrm{Au}, \mathrm{Ag}$, and iron oxide $\left(\mathrm{Fe}_{3} \mathrm{O}_{4}\right)$ NPs with the chromogenic LAL assay of Associates of Cape Cod (endpoint readout at $540 \mathrm{~nm}$ ) and in parallel with the ECVAM-approved PBMC activation assay (IL- 6 production) (39). The endotoxin contamination detected by the LAL assay was confirmed by the PBMC activation assay only for Au NPs, but not for $\mathrm{Ag}$ and $\mathrm{Fe}_{3} \mathrm{O}_{4} \mathrm{NPs}$. This is probably due to the interference of NPs with some elements in the bioassay. Most likely, the NPs interfere with the ELISA-based IL-6 detection process by interfering with antigen/antibody interaction, adsorbing and subtracting IL-6, or quenching the optical signal that indicates the presence of IL-6. Thus, the biological assays also need an accurate characterization and validation before their results can be used to detect endotoxin in ENM. Table 1 summarizes the pros and cons of different endotoxin evaluation methods for EMN.

\section{CONCLUSION AND FUTURE PERSPECTIVE}

To reliably assess safety of ENM, either intended for medical use or included in commercial products, it is important to take into careful consideration the presence of unwanted bioactive contaminants, of which bacterial endotoxin is most common and abundant. This would eliminate misinterpretation of experimental results and erroneous attribution to ENM of toxic effects that may be entirely due to contaminants. Thus, nanosafety/nanomedicine researchers and regulators should be aware of the possible contamination of ENM with highly inflammatory contaminants such as endotoxin and design and adopt appropriately designed assays. Likewise, chemists/producers should design their synthesis processes to minimize endotoxin contamination. Furthermore, since the methods for endotoxin assessment in ENM are still challenging (Table 1) and the regulations on nanoproducts are still incomplete, robust strategies and bespoke assays need to be developed for endotoxin evaluation in ENM.

\section{AUTHOR CONTRIBUTIONS}

YL wrote the paper, MF revised it, and DB contributed to writing and critically revised it.

\section{ACKNOWLEDGMENTS}

The authors would like to thank Dr. Alessandro Ponti (CNR, Milano, Italy) for having provided several kinds of ENM. The authors are grateful to Prof. Victor F. Puntes (Institut Català de Nanociència i Nanotecnologia, Barcelona, Spain) for helpful discussion on LPS interaction with ENM.

\section{FUNDING}

This work was supported by the EU Commission projects NANoREG (FP7 grant no. 310584) and PANDORA (H2020 grant no. 671881), the cluster project Medintech (CTN01_00177_96) of the Italian Ministry of Education, University and Research, and the Veterans Affairs Merit Review Award 5I01BX001228, NIH/ NCI R01CA197919. 


\section{REFERENCES}

1. Savolainen K, Backman U, Brouwer D, Fadeel B, Fernandes T, Kuhlbusch T, et al. Nanosafety in Europe 2015-2025: Towards Safe and Sustainable Nanomaterials and Nanotechnology Innovations. Helsinki: Finnish Institute of Occupational Health (2013).

2. Nel A, Xia T, Mädler L, Li N. Toxic potential of materials at the nanolevel. Science (2006) 311(5761):622-7. doi:10.1126/science.1114397

3. Johnston HJ, Hutchison G, Christensen FM, Peters S, Hankin S, Stone V. A review of the in vivo and in vitro toxicity of silver and gold particulates: particle attributes and biological mechanisms responsible for the observed toxicity. Crit Rev Toxicol (2010) 40(4):328-46. doi:10.3109/10408440903453074

4. Li Y, Liu Y, Fu Y, Wei T, Le Guyader L, Gao G, et al. The triggering of apoptosis in macrophages by pristine graphene through the MAPK and TGF-beta signaling pathways. Biomaterials (2012) 33:402-11. doi:10.1016/j. biomaterials.2011.09.091

5. Shannahan JH, Kodavanti UP, Brown JM. Manufactured and airborne nanoparticle cardiopulmonary interactions: a review of mechanisms and the possible contribution of mast cells. Inhal Toxicol (2012) 24(5):320-39. doi:10. 3109/08958378.2012.668229

6. Li Y, Monteiro-Riviere NA. Mechanisms of cell uptake, inflammatory potential and protein corona effects with gold nanoparticles. Nanomedicine (2016) 11(24):3185-203. doi:10.2217/nnm-2016-0303

7. Rabolli V, Lison D, Huaux F. The complex cascade of cellular events governing inflammasome activation and IL-1 $\beta$ processing in response to inhaled particles. Part Fibre Toxicol (2016) 13(1):40. doi:10.1186/ s12989-016-0150-8

8. Li Y, Boraschi D. Endotoxin contamination: a key element in the interpretation of nanosafety studies. Nanomedicine (Lond) (2016) 11(3):269-87. doi: $10.2217 / \mathrm{nnm} .15 .196$

9. Lu YC, Yeh WC, Ohashi PS. LPS/TLR4 signal transduction pathway. Cytokine (2008) 42(2):145-51. doi:10.1016/j.cyto.2008.01.006

10. Janeway CA Jr, Medzhitov R. Innate immune recognition. Annu Rev Immunol (2002) 20(1):197-216. doi:10.1146/annurev.immunol.20.083001.084359

11. Danner RL, Elin R, Hosseini J, Wesley R, Reilly J, Parillo J. Endotoxemia in human septic shock. Chest (1991) 99(1):169-75. doi:10.1378/chest.99.1.169

12. Braun-Fahrländer C, Riedler J, Herz U, Eder W, Waser M, Grize L, et al. Environmental exposure to endotoxin and its relation to asthma in school-age children. N Engl J Med (2002) 347(12):869-77. doi:10.1056/ NEJMoa020057

13. Liu AH. Endotoxin exposure in allergy and asthma: reconciling a paradox. J Allergy ClinImmunol (2002) 109(3):379-92. doi:10.1067/mai.2002.122157

14. Rylander R. Review: endotoxin in the environment - exposure and effects. J Endotoxin Res (2002) 8(4):241-52. doi:10.1179/096805102125000452

15. Malyala P, Singh M. Endotoxin limits in formulations for preclinical research. J Pharm Sci (2008) 97(6):2041-4. doi:10.1002/jps.21152

16. Sandle T. A comparative study of different methods for endotoxin destruction. Am Pharm Rev (2013) 16(6):15-7.

17. Gorbet MB, Sefton MV. Endotoxin: the uninvited guest. Biomaterials (2005) 26(34):6811-7. doi:10.1016/j.biomaterials.2005.04.063

18. Williams KL. Endotoxins: Pyrogens, LAL Testing and Depyrogenation. New York, NY: Informa Healthcare (2007).

19. França Á, Pelaz B, Moros M, Sánchez-Espinel C, Hernández A, FernándezLópez C, et al. Sterilization matters: consequences of different sterilization techniques on gold nanoparticles. Small (2010) 6(1):89-95. doi:10.1002/ smll.200901006

20. Vallhov H, Qin J, Johansson SM, Ahlborg N, Muhammed MA, Scheynius A, et al. The importance of an endotoxin-free environment during the production of nanoparticles used in medical applications. Nano Lett (2006) 6(8):1682-6. doi:10.1021/nl060860z

21. Jones CF, Grainger DW. In vitro assessments of nanomaterial toxicity. $A d v$ Drug Deliv Rev (2009) 61(6):438-56. doi:10.1016/j.addr.2009.03.005

22. Hirayama C, Sakata M. Chromatographic removal of endotoxin from protein solutions by polymer particles. J Chromatogr B Analyt Technol Biomed Life Sci (2002) 781:419-32. doi:10.1016/S1570-0232(02)00430-0

23. Li Y, Tran N, Puntes VF, Boraschi D. Bacterial endotoxin binds to the surface of gold nanoparticles and triggers inflammation. 7th International Nanotoxicology Congress - Nanotox 2014; Antalya, Turkey (2014).
24. Darkow R, Groth T, Albrecht W, Lützow K, Paul D. Functionalized nanoparticles for endotoxin binding in aqueous solutions. Biomaterials (1999) 20(14):1277-83. doi:10.1016/S0142-9612(99)00022-8

25. Bromberg L, Chang EP, Alvarez-Lorenzo C, Magarinos B, Concheiro A, Hatton TA. Binding of functionalized paramagnetic nanoparticles to bacterial lipopolysaccharides and DNA. Langmuir (2010) 26(11):8829-35. doi:10.1021/ la904589p

26. Peula-García J, Molina-Bolivar J, Velasco J, Rojas A, Galisteo-González F. Interaction of bacterial endotoxine (lipopolysaccharide) with latex particles: application to latex agglutination immunoassays. J Colloid Interface Sci (2002) 245(2):230-6. doi:10.1006/jcis.2001.7958

27. Abadeer NS, Fulop G, Chen S, Kall M, Murphy CJ. Interactions of bacterial lipopolysaccharides with gold nanorod surfaces investigated by refractometric sensing. ACS Appl Mater Interfaces (2015) 7(44):24915-25. doi:10.1021/ acsami.5b08440

28. Oostingh GJ, Casals E, Italiani P, Colognato R, Stritzinger R, Ponti J, et al. Problems and challenges in the development and validation of human cellbased assays to determine nanoparticle-induced immunomodulatory effects. Part Fibre Toxicol (2011) 8(1):8. doi:10.1186/1743-8977-8-8

29. Murali K, Kenesei K, Li Y, Demeter K, Környei Z, Madarász E. Uptake and bio-reactivity of polystyrene nanoparticles is affected by surface modifications, ageing and LPS adsorption: in vitro studies on neural tissue cells. Nanoscale (2015) 7(9):4199-210. doi:10.1039/c4nr06849a

30. Li Y, Italiani P, Casals E, Valkenborg D, Mertens I, Baggerman G, et al. Assessing the immunosafety of engineered nanoparticles with a novel in vitro model based on human primary monocytes. ACS Appl Mater Interfaces (2016) 8(42):28437-47. doi:10.1021/acsami.6b06278

31. Afonina IS, Müller C, Martin SJ, Beyaert R. Proteolytic processing of interleukin-1 family cytokines: variations on a common theme. Immunity (2015) 42(6):991-1004. doi:10.1016/j.immuni.2015.06.003

32. Chen G-Y, Yang H-J, Lu C-H, Chao Y-C, Hwang S-M, Chen C-L, et al. Simultaneous induction of autophagy and toll-like receptor signaling pathways by graphene oxide. Biomaterials (2012) 33(27):6559-69. doi:10.1016/ j.biomaterials.2012.05.064

33. Chen Z, Liu Y, Sun B, Li H, Dong J, Zhang L, et al. Polyhydroxylated metallofullerenols stimulate IL-1 $\beta$ secretion of macrophage through TLRs/ MyD88/NF-кB pathway and NLRP3 inflammasome activation. Small (2014) 10(12):2362-72. doi:10.1002/smll.201470069

34. Bastús NG, Sánchez-Tilló E, Pujals S, Farrera C, Kogan MJ, Giralt E, et al. Peptides conjugated to gold nanoparticles induce macrophage activation. Mol Immunol (2009) 46(4):743-8. doi:10.1016/j.molimm.2008.08.277

35. Qu G, Liu S, Zhang S, Wang L, Wang X, Sun B, et al. Graphene oxide induces toll-like receptor 4 (TLR4)-dependent necrosis in macrophages. ACS Nano (2013) 7(7):5732-45. doi:10.1021/nn402330b

36. Dobrovolskaia MA, Neun BW, Clogston JD, Ding H, Ljubimova J, McNeil SE. Ambiguities in applying traditional Limulus amebocyte lysate tests to quantify endotoxin in nanoparticle formulations. Nanomedicine (2010) 5(4):555-62. doi: $10.2217 / \mathrm{nnm} .10 .29$

37. Smulders S, Kaiser JP, Zuin S, Van Landuyt KL, Golanski L, Vanoirbeek J, et al. Contamination of nanoparticles by endotoxin: evaluation of different test methods. Part Fibre Toxicol (2012) 9(1):41. doi:10.1186/1743-8977-9-41

38. Dobrovolskaia MA, Neun BW, Clogston JD, Grossman JH, McNeil SE. Choice of method for endotoxin detection depends on nanoformulation. Nanomedicine (Lond) (2014) 9(12):1847-56. doi:10.2217/nnm.13.157

39. Li Y, Italiani P, Casals E, Tran N, Puntes VF, Boraschi D. Optimising the use of commercial LAL assays for the analysis of endotoxin contamination in metal colloids and metal oxide nanoparticles. Nanotoxicology (2015) 9(4):462-73. doi:10.3109/17435390.2014.948090

40. Mukherjee SP, Lozano N, Kucki M, Del Rio-Castillo AE, Newman L, Vázquez E, et al. Detection of endotoxin contamination of graphene based materials using the TNF- $\alpha$ expression test and guidelines for endotoxin-free graphene oxide production. PLoS One (2016) 11(11):e0166816. doi:10.1371/ journal.pone.0166816

41. FDA. Guideline on Validation of the Limulus Amebocyte Lysate Test as an EndProduct Endotoxin Test for Human and Animal Parenteral Drugs, Biological Products, and Medical Devices. U.S. Department of Health and Human Services, Public Health Service, Food and Drug Administration (1987). 
42. ChP. Bacterial endotoxins test. Chinese Pharmacopoeia. (2005).

43. EP. Bacterial endotoxins. European Pharmacopoeia 5.0. (2005). p. 161-8.

44. USP. Chapter 85: bacterial endotoxins test. United States Pharmacopeia. Rockville: United States Pharmacopeial Convention (2005).

45. ISO. ISO/FDIS 29701: Nanotechnologies - Endotoxin Test on Nanomaterial Samples for In Vitro Systems - Limulus Amebocyte Lysate (LAL) Test. (2010). Available from: http://www.iso.org/iso/iso_catalogue/catalogue_tc/catalogue_detail.htm?csnumber $=45640$

46. Brooks R, Wimhurst J, Rushton N. Endotoxin contamination of particles produces misleading inflammatory cytokine responses from macrophages in vitro. J Bone Joint Surg Br (2002) 84(2):295-9. doi:10.1302/0301-620X.84B2.12061

47. Kucki M, Cavelius C, Kraegeloh A. Interference of silica nanoparticles with the traditional Limulus amebocyte lysate gel clot assay. Innate Immun (2014) 20(3):327-36. doi:10.1177/1753425913492833
48. FDA, CBER, CMV, CDRH, ORA. Guidance for Industry. Pyrogen and Endotoxins Testing: Questions and Answers. (2012).

Conflict of Interest Statement: The authors declare that the research was conducted in the absence of any commercial or financial relationships that could be construed as a potential conflict of interest.

Copyright (c) 2017 Li, Fujita and Boraschi. This is an open-access article distributed under the terms of the Creative Commons Attribution License (CC BY). The use, distribution or reproduction in other forums is permitted, provided the original author(s) or licensor are credited and that the original publication in this journal is cited, in accordance with accepted academic practice. No use, distribution or reproduction is permitted which does not comply with these terms. 